\title{
Stromal cell contribution to human follicular lymphoma pathogenesis
}

\author{
Frédéric Mourcin ${ }^{1,2,3}$, Céline Pangault ${ }^{1,2,4}$, Rada Amin-Ali ${ }^{1,2}$, Patricia Amé-Thomas ${ }^{1,2,4}$ and Karin Tarte ${ }^{1,2,3,4}$ * \\ 1 INSERM, UMR U917, Rennes, France \\ 2 Université Rennes 1, Rennes, France \\ ${ }^{3}$ Etablissement Français du Sang, Bretagne, Rennes, France \\ ${ }^{4}$ Service ITeCH, Pôle de Biologie, CHU de Rennes, Rennes, France
}

\section{Edited by:}

Christopher G. Mueller, Centre National de la Recherche Scientifique, France

\section{Reviewed by:}

Mark C. Coles, University of York, UK Laura Santambrogio, Albert Einstein College of Medicine, USA

*Correspondence:

Karin Tarte, Faculté de Médecine, INSERM, UMR U917, 2 Avenue du Pr Léon Bernard, 35043 Rennes, France. e-mail:karin.tarte@univ-rennes1.fr
Follicular lymphoma $(\mathrm{FL})$ is the prototypical model of indolent B cell lymphoma displaying a strong dependence on a specialized cell microenvironment mimicking normal germinal center. Within malignant cell niches in invaded lymph nodes and bone marrow, external stimuli provided by infiltrating stromal cells make a pivotal contribution to disease development, progression, and drug resistance. The crosstalk between FL B cells and stromal cells is bidirectional, causing activation of both partners. In agreement, FL stromal cells exhibit specific phenotypic, transcriptomic, and functional properties. This review highlights the critical pathways involved in the direct tumor-promoting activity of stromal cells but also their role in the organization of FL cell niche through the recruitment of accessory immune cells and their polarization to a B cell supportive phenotype. Finally, deciphering the interplay between stromal cells and FL cells provides potential new therapeutic targets with the aim to mobilize malignant cells outside their protective microenvironment and increase their sensitivity to conventional treatment.

Keywords: B cells, bone marrow, lymph nodes, cell interactions, stromal cells

\section{B CELL LYMPHOMA MICROENVIRONMENT}

Human mature B cell lymphomas represent a heterogeneous group of neoplasias characterized by recurrent genetic abnormalities and pathway dependencies. Each lymphoma subtype could be assigned to a peculiar stage of normal B cell differentiation, as judged by gene expression profiling and phenotype (Shaffer et al., 2012). In some of them, malignant B cell proliferation, survival, and drug resistance are strongly dependent on a combination of external stimuli delivered by the microenvironment within specific niches in invaded lymph nodes (LN) and bone marrow (BM; Burger et al., 2009). This is particularly true in follicular lymphoma (FL), the most frequent indolent lymphoma, which results from the malignant transformation of germinal center (GC)-derived B cells (Figure 1). Whereas over $90 \%$ of FL cases display a $B C L 2 / I G H$ translocation, this early event, occurring as a mistake of $\mathrm{V}(\mathrm{D}) \mathrm{J}$ recombination in the $\mathrm{BM}$, could be detected at low frequency within recirculating post-GC memory B cells of most healthy individuals (Roulland et al., 2011). These $t(14 ; 18)^{\text {pos }}$ cells exhibit additional characteristics that stand as hallmarks of FL cells; i.e., CD10 expression, unleashed AID activity, persistence of surface IgM despite active class-switch recombination on the translocated allele; are thus called follicular-lymphoma like cells. Given that the actual prevalence of $\mathrm{FL}$ is around $0.03 \%$, it is clear that FL pathogenesis requires additional oncogenic events as well as a progressive modification of the composition and organization of tumor microenvironment (Bende et al., 2007). Among the recurrent complementary hits identified in FL patients, several alterations target the transcriptional and epigenetic pathways including inactivation of CREBBP/EP300 acetyltransferases,
MLL2 methyltransferase, and MEF2B, involved in the recruitment of histone-modifying enzymes, and gain-of-function mutations of EZH2 polycomb gene (Shaffer et al., 2012). Recently, a frequent inactivation of the soluble inhibitory receptor EPHA7 was also reported (Oricchio et al., 2011). This inactivation hinders the blockade by EPHA7 of the ephrin migratory pathway induced by cell-cell contact.

In agreement, genetic alterations and modification of the microenvironment are not independent transformation mechanisms since several FL-specific genetic alterations are not oncogenic per se but favor specific interactions with neighboring cells. Among them, the frequent mutations of TNFRSF14/HVEM could play a role in the maintenance of the functional tumor cell niche (Launay et al., 2012; Pasero et al., 2012). In fact, binding of HVEM to its receptor BTLA delivers an inhibitory signal and BTLA is strongly expressed on FL-supportive follicular helper $\mathrm{T}$ cells $\left(\mathrm{T}_{\mathrm{FH}}\right)$ within malignant follicles (see below). In addition, nearly all FL-derived immunoglobulin variable regions display unusual sites for $\mathrm{N}$-linked glycosylation, introduced during somatic hypermutation process, and reflecting positive selection associated to lymphomagenesis (Stevenson and Stevenson, 2012). Glycans added to these motifs are atypical in terminating at high mannose that interact with C-type lectins on the surface of surrounding cells and trigger BCR engagement. This functional bridge could mimic for continuous antigen stimulation to promote survival of FL cells (Coelho et al., 2010). About $30 \%$ of FL finally transform into aggressive diffuse large B cell lymphomas (DLBCL) that are less dependent on their microenvironment. 


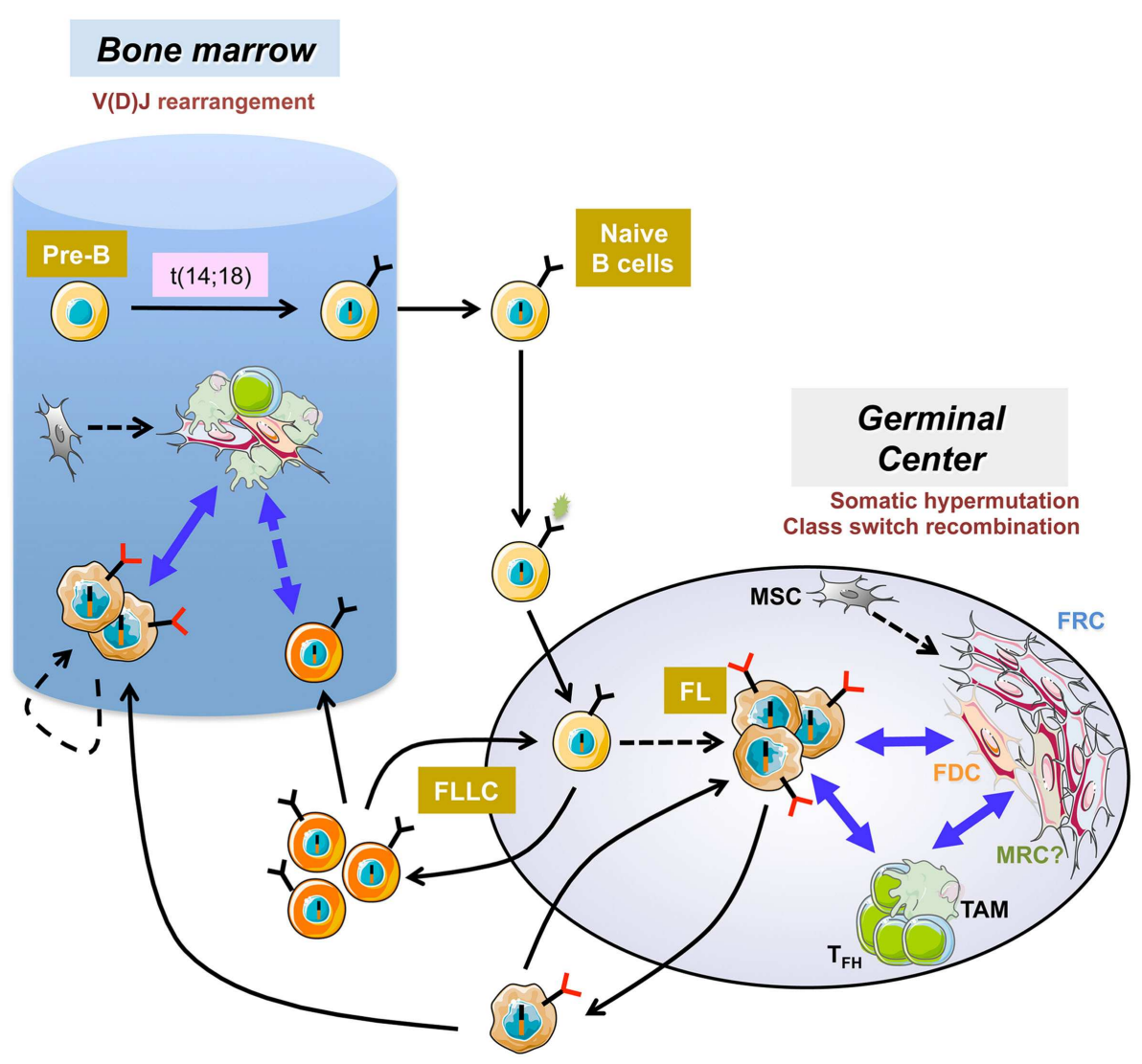

FIGURE 1 | Follicular lymphoma pathogenesis. The first step of follicular lymphoma (FL) development occurs in the bone marrow as a mistake in $V(D) J$ rearrangement and leads to the ectopic expression of the antiapoptotic protein bcl2. After antigen encounter, naive B cells harboring the $t(14 ; 18)$ reach the germinal center where they display a selective growth advantage and could extensively recirculate as atypical IgMpos low affinity memory B cells called follicular-lymphoma like cells (FLLC). Iterative reentries into germinal centers allow the acquisition of additional genetic alterations. The relationship between FLLC and FL is not formerly demonstrated but the hypothesis is that FLLC contain premalignant intermediates that could transform in some patients into FL. FL cells remain strongly dependent on bidirectional crosstalk with heterogeneous stromal cells, including activated fibroblastic reticular cells (FRC), altered follicular dendritic cells (FDC), and perhaps marginal reticular cells (MRC) of unknown origin and infiltrating immune cells including tumor-associated macrophages (TAM) and follicular helper T cells $\left(\mathrm{T}_{\mathrm{FH}}\right)$. FL also developed in the bone marrow where B-cell clones could evolve independently within ectopic specific FL-supportive niches.
Microarray analyses have revealed that the clinical outcome of FL patients is primarily predicted by molecular features of non-malignant cells (Dave et al., 2004). Moreover, immunohistochemical studies have identified a large panel of predictive markers reflecting the number, activation, and/or spatial distribution of infiltrating immune non-B cell subsets, including tumorassociated macrophages (TAM) and CD4 ${ }^{\text {pos }} \mathrm{T}$ cells (Relander et al., 2010). Besides immune cells, three main stromal cell subsets have been described within normal LN: (i) fibroblastic reticular cells (FRC) recruit mature dendritic cells and naïve $\mathrm{B}$ and $\mathrm{T}$ lymphocytes through the production of CCL19, CCL21, and CXCL12, promote cell-cell interactions within the $\mathrm{T}$ cell zone, and are involved in $\mathrm{T}$ cell self-tolerance and tissue tropism imprinting; (ii) follicular dendritic cells (FDC) drive CXCL13-dependent B cell attraction within $\mathrm{GC}$ where they concentrate unprocessed antigens and promote the selection of high affinity B cells; (iii) marginal reticular cells (MRC) deliver small antigens to cognate $B$ cells through a network of follicular conduits (Mueller and Germain,
2009; Roozendaal and Mebius, 2011). It has long been assumed that some tumor conducive stromal cell niches are shaped within FL LN. In fact, FL LN exhibit a uniform and marked activation of transglutaminase expressing FRC network (Thomazy et al., 2003), whereas FDC display an undifferentiated phenotype (Chang et al., 2003; Jin et al., 2011). MRC have never been evaluated in human lymphomas. More generally a functional characterization of the heterogeneous stromal cell network that is found within malignant follicles is currently lacking. In addition, the in situ distribution of lymphoid stromal cell subsets relative to malignant B cells and to the other FL-supporting cell subsets and their activation status in malignant follicles remains unknown.

Follicular lymphoma is generally a disseminated disease and $\mathrm{BM}$ is involved in up to $70 \%$ of patients at diagnosis (Canioni et al., 2004). BM infiltration is characterized by the ectopic development of heterogeneous lymphoid-like stromal cells of unknown origin that are found admixed with malignant $B$ cells and $\mathrm{CD} 44^{\text {pos }} \mathrm{T}$ cells among nodular aggregates (Vega et al., 2002). 
Even if BM malignant B cells retain their main follicular features, several morphologic, phenotypic, and genetic differences have been reported among tumor cells found within LN and BM. In particular, BM FL cells are characterized by a lower cytological grade and proliferation (Bognar et al., 2005; Rajnai et al., 2012), and exhibit a distinct transcriptomic profile revealing a downregulation of genes involved in cell proliferation and DNA repair (our unpublished data). In addition, despite a common clonal origin, analysis of intraclonal evolution reveals that a significant part of the BM infiltration evolves independently from the tumor clones detected in the LN indicating that BM provides a specific nonlymphoid malignant cell niche (Bognar et al., 2005; Ruminy et al., 2008). Recently, major differences in the cell composition of BM and LN microenvironments have been highlighted (Rajnai et al., 2012; Wahlin et al., 2012) thus paving the way for dedicated studies evaluating the impact of these variations on the behavior of malignant FL cell clones.

Several experimental limitations have hampered a full understanding of the role of stromal cells in FL pathogenesis: (i) the lack of B cell line reflecting the untransformed indolent stage of FL leading to the use of aggressive GC-lymphoma cell lines; (ii) the limited accessibility of tumor biopsies and the high propensity of primary FL cells to undergo apoptosis in vitro; (iii) the impossibility to maintain fully functional human FDC in culture; (iv) the heterogeneity of stromal cell subsets that remain poorly understood in human; (v) the inherent flaws of human FL $B$ cell xenotransplantation into immunocompromised mice that are devoid of structured secondary lymphoid organs; (vi) the lack of validated relevant mouse model of FL. Nevertheless, even if these pitfalls should be carefully kept in mind, some recent studies have provided interesting results about lymphoma-permissive stromal cells, revealing both a direct B cell supportive effect and an indirect activity on the orchestration of the FL cell niche.

\section{DIRECT PROTUMORAL ACTIVITIES OF STROMAL CELLS}

Interplay between lymphoma cells and their microenvironment provides pivotal signals for malignant cell recruitment and growth (Figure 2). First, stromal cells have been involved in the homing of FL B cells that display a CXCR $4{ }^{\text {hi }} \mathrm{CXCR} 5{ }^{\text {hi }} \mathrm{CCR} 7{ }^{\text {lo }}$ phenotype, resembling to normal GC B cells (Lopez-Giral et al., 2004). We have in particular identified the CXCR4-ligand CXCL12 as the central chemokine in the recruitment of FL cells by both BM and LN-derived stromal cells (Amé-Thomas et al., 2007). Interestingly, CXCL13 has an additive effect with CXCL12 for the migration of FL cells in vitro (Husson et al., 2002) and these two chemokines, both produced by FDC in vivo, could contribute to the follicular localization of malignant cells. In the E $\mu$-Myc transgenic mouse model, CCR7 was elegantly reported to drive the specific homing of malignant $\mathrm{B}$ cells to the $\mathrm{T}$ cell zone where their promote the formation of a lymphoma-supportive stromal cell niche (Rehm et al., 2011). The potential role of CCR7 in human FL is less clear, given its low expression on malignant clones. However, we recently underlined using Affymetrix microarrays that CCR7 expression is low but upregulated in FL cells compared to normal centroblasts and centrocytes (our unpublished data). The cues that guide normal GC B cell migration have been recently described in mice and involve fine coregulation of CCR7, sphingosine 1-phosphate

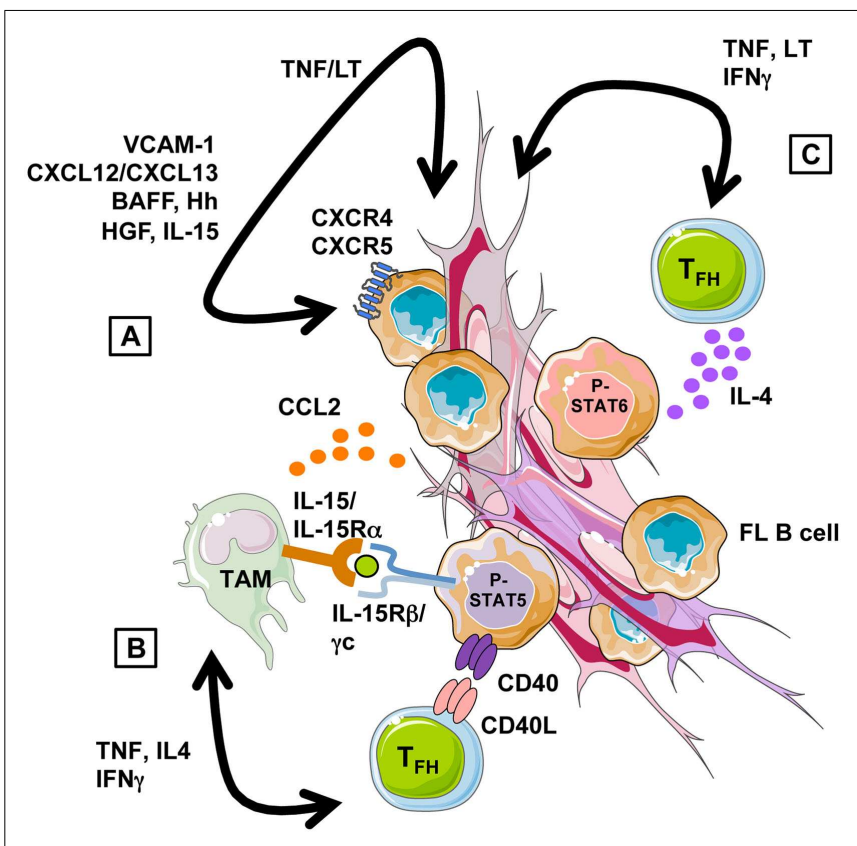

FIGURE 2 | Follicular lymphoma cell niche. (A) Stromal cells recruit and support directly the growth of FL B cells through a combination of adhesion molecules, chemokines, and cytokines. Their supportive properties are strongly influenced by the local cytokine context, in particular by TNF- $\alpha$ and $\mathrm{LT}-\alpha 1 \beta 2$ that are overexpressed by malignant $\mathrm{B}$ cells and promote lymphoid stromal cell differentiation. (B) FL-MSC overexpress the chemokine CCL2 that promotes monocyte recruitment and polarization into TAM-like cells. FL-TAM overexpress IL-15 that triggers, in cooperation with TFH-derived CD40L, STAT5-dependent FL B cell activation. (C) FL-TFH overexpress TNF- $\alpha$ and $L T-\alpha 1 \beta 2$, which favor stromal cell engagement into FRC differentiation, but also IL-4 that drive STAT6-dependent B-cell activation and contribute to the induction of TAM phenotype.

(S1P) receptor type 2 (SIPR2, also called S1P2), and Epstein-Barr virus-induced gene 2 (EBI2, also known as GPR183) whose ligands are produced by various lymphoid stromal cell subsets. CCR7 is the receptor for CCL19/CCL21 produced by FRC of the T cell zone. SIPR2 belongs to the family receptors for S1P, a lipid signaling molecule presents in a decaying gradient in the follicle. S1PR2 engagement by S1P inhibits cell migration and is involved in the retention of GC B cells. Finally, the EBI2 ligand $7 \alpha, 25$ dihydroxycholesterol is suggested to be present at high levels in outer follicle and interfollicular regions. Briefly, normal antigenactivated B cells upregulate CCR7 and EBI2 and localize to the $\mathrm{T}$-B border zone before migrating to the outer follicle region. By day 4, the downregulation of CCR7 and EBI2, and the upregulation of S1PR2 direct their movement and their confinement to the follicle center, allowing GC formation (Pereira et al., 2010; Green and Cyster, 2012). Interestingly, S1PR2 is downregulated in FL whereas EBI2 is similarly expressed in FL cells and normal GC B cells (our unpublished results). How the specific migratory profile of FL B cells compared to their normal counterpart, i.e., similarly high expression of CXCR4 and CXCR5, similarly low expression of EBI2, higher expression of CCR7, and lower expression of S1PR2, could be involved in their dissemination pattern is a fascinating issue. In addition, even if the mechanisms of S1PR2 lymphoma 
suppressor function remain to be elucidated, S1PR2-deficient mice develop tumors displaying histologic and molecular features of GC-derived DLBCL and S1PR2 is aberrantly mutated in $26 \%$ of human DLBCL (Cattoretti et al., 2009).

Besides migration, stromal cells provide essential survival factors to FL B cells. Among them, hedgehog ( $\mathrm{Hh})$ ligands are secreted by BM and LN stromal cells, including FRC and FDC, and prevent spontaneous normal and malignant GC B cell apoptosis (Sacedon et al., 2005; Dierks et al., 2007). In addition, paracrine Hh signaling induces the upregulation of the drug transporter ATP-binding cassette (ABC) G2 and could be involved in stroma-mediated chemotolerance in indolent lymphomas (Singh et al., 2010). The gain of cell-autonomous activation of Hh pathway in DLBCL compared to FL, likely contributes to stroma-independence in this aggressive disease (Kim et al., 2009). Drug resistance has also been associated to the induction by stromal cells of microRNA-181a in malignant B cells, promoting a downregulation of the proapoptotic protein Bim (Lwin et al., 2010). However, whereas regulation of miRNA expression in lymphoma cells by stromal cells is probably a more common event than previously anticipated (Lin et al., 2011), the mechanisms of this modulation remain unsolved. VLA4-dependent adhesion to stromal cells also protects FL B cells from apoptosis induced by therapeutic antibodies, in particular the anti-CD20 antibody rituximab (Mraz et al., 2011). Interestingly, the VLA-4-ligand VCAM-1/CD106 is upregulated during lymphoid stroma differentiation with a very strong expression in FDC. BAFF, IL-15, and HGF are also produced by FDC and have been proposed to contribute to the antiapoptotic effect of stromal cells on normal and malignant GC B cell growth (Park et al., 2004; Tjin et al., 2005, 2006; Mueller et al., 2007; Lwin et al., 2009; Epron et al., 2012), whereas the role of FDC-derived Wnt5a and Notch ligands in GC-derived lymphomas has not been explored to date (Yoon et al., 2009; Kim et al., 2012).

Importantly, neoplastic B cell-stroma interaction should really be considered as a bidirectional crosstalk. We have previously demonstrated that human secondary lymphoid organs contain bona fide mesenchymal stromal cells (MSC) that could be committed, like BM-MSC, to FRC differentiation in response to a combination of tumor necrosis factor (TNF)- $\alpha$ and lymphotoxin (LT) $-\alpha 1 \beta 2$, the two main factors involved in the differentiation and maintenance of secondary lymphoid organs (Amé-Thomas et al., 2007). These FRC-like cells are more powerful than resting MSC to support malignant B cell survival. Moreover, malignant B cells themselves could trigger such FRC engagement, at least in part through the release of high levels of TNF- $\alpha$ and LT- $\alpha 1 \beta 2$ (Guilloton et al., 2012). In agreement, MSC obtained from invaded BM of FL patients (FL-MSC) are already committed to a FRC-like differentiation, and support more efficiently the growth of malignant $B$ cells than MSC obtained from BM of healthy donors (HDMSC). FL-MSC display a specific gene expression profile (Guilloton et al., 2012) and it would be of major importance to identify the mechanisms of their increased direct tumor-promoting capacity.

Finally, the activity of stromal cells on malignant B cells could be modulated depending on the cytokine context. We have demonstrated that human MSC, in particular after commitment to a FRC-like phenotype, could express indoleamine-2,3 dioxygenase in response to interferon (IFN) $-\gamma$ signaling, leading to an inhibition of normal and malignant $\mathrm{B}$ cell proliferation but not survival (Maby-El Hajjami et al., 2009). Of note, IFNG is upregulated within FL microenvironment, compared to reactive nonmalignant LN. Similarly, mice FRC could express nitric oxide synthase 2 after priming by IFN- $\gamma$ and could thereafter inhibit $\mathrm{T}$ cell proliferation to control $\mathrm{T}$ cell expansion (Lukacs-Kornek et al., 2011; Siegert et al., 2011). In addition, it has been suggested that adhesion of lymphoma B cells to BM stroma could induce a p27-dependent reversible cell cycle arrest, promoting cell survival, and drug resistance (Lwin et al., 2007). Finally, stromal cells are well known to secrete tumor-transforming growth factor (TGF)$\beta$ that inhibits the proliferation of GC-derived B cell lines in a Smad1-dependent manner (Munoz et al., 2004). Altogether these data demonstrate that stromal cells finely regulate the behavior of lymphoma B cells that, in turn, affect their differentiation and activation.

\section{INDIRECT PROTUMORAL ACTIVITIES OF STROMAL CELLS}

Besides this direct lymphoma-supportive activity, stromal cells could also interact with non-malignant tumor-infiltrating cells and orchestrate FL cell niches. We have in particular demonstrated that FL-MSC overexpress CCL2 at both RNA and protein levels compared to HD-MSC (Guilloton et al., 2012). Interestingly CCL2 is detectable at higher levels within FL-invaded BM compared to normal BM. Moreover, CCL2 is upregulated in HD-MSC by coculture with malignant $B$ cells in a TNF- $\alpha$-dependent manner. Tumor-derived CCL2 recruits monocytes in several malignant models (Roca et al., 2009; Qian et al., 2011). We have demonstrated that CCL2 specifically contributes to monocyte recruitment by FL-MSC that in turn trigger their differentiation toward a proangiogenic and anti-inflammatory TAM-like phenotype (Guilloton et al., 2012). Furthermore, stromal cells and macrophages cooperate to sustain malignant B cell survival and proliferation in vitro. The reverse activity of macrophages on MSC remains to be evaluated in this context. The poor prognostic value of a high TAM content in FL patients treated with conventional chemotherapy has been reproducibly documented (Relander et al., 2010). However the precise mechanism of the supportive activity of macrophages toward neoplastic B cells remains unknown. Among the candidates, we recently demonstrated that purified FL-TAM overexpress IL-15 that cooperates with T cell-derived CD40L signal to sustain FL cell growth (Epron et al., 2012). In DLBCL, BAFF was also proposed as a monocyte-derived survival factor (Mueller et al., 2007). Another highly interesting signaling pathway is the expression of C-type lectins by myeloid cells that could crosslink the mannosylated FL BCR independently of antigen specificity (Stevenson and Stevenson, 2012).

Another crucial FL-supportive cell subset is the $\mathrm{CD} 4^{\text {pos }}$ CXCR5 ${ }^{\text {hi }}$ ICOS ${ }^{\text {hi }}$ PD- $1{ }^{\text {hi }} \mathrm{T}_{\mathrm{FH}}$ compartment. $\mathrm{T}_{\mathrm{FH}}$ provide survival signals to antigen-selected normal GC B cells and help them to achieve class-switch recombination and terminal differentiation into antibody-secreting plasma cells (Crotty, 2011). In human, $\mathrm{T}_{\mathrm{FH}}$ are also a major source of CXCL13 within follicles. We have first demonstrated that $\mathrm{T}_{\mathrm{FH}}$ could be found in very high numbers within the FL cell niche and efficiently support the survival of FL cells in vitro, unlike non-TFH CD4 ${ }^{\text {pos }} \mathrm{T}$ cells (Amé-Thomas et al., 2012). In agreement, FL- $\mathrm{T}_{\mathrm{FH}}$ overexpress several genes directly 
involved in B cell activation, in particular CD40LG and IL4, and we confirmed the importance of the $\mathrm{T}_{\mathrm{FH}}$-dependent IL4 centered pathway (Pangault et al., 2010). Interestingly, compared to tonsil$\mathrm{T}_{\mathrm{FH}}, \mathrm{FL}-\mathrm{T}_{\mathrm{FH}}$ also overexpress some genes involved in the crosstalk with stromal cells, in particular TNF and LTA, that could favor the differentiation and maintenance of lymphoid stromal cells and the production of CCL2. Lymphoid stromal cells favor $\mathrm{T}_{\mathrm{FH}}$ survival in vitro (our unpublished results) suggesting another positive loop that sustains lymphomagenesis.

Follicular lymphoma cell niche should be thus considered as a highly intricate network of heterogeneous cell subsets where stromal cells directly promote tumor growth but play also a central role as global organizers of the malignant microenvironment through the regulation of non-B cell recruitment, survival, and polarization.

\section{STROMAL CELLS AS THERAPEUTIC TARGETS IN LYMPHOMA}

Given the preeminent role of stromal cells within FL microenvironment, they progressively emerged as promising therapeutic targets in this essentially incurable disease. A first approach is to transiently mobilize malignant B cells outside their protective niches to render them more sensitive to chemo- and immunotherapy. CXCR4 antagonists, such as plerixafor (AMD3100), could be combined with drugs targeting the malignant cells, such as anti-CD20 antibodies, to increase their activity (Hu et al., 2012). Cell-penetrating lipidated peptides targeting CXCR4 intracellular domains also significantly increase the antitumoral activity of rituximab in vitro and in vivo (O'Callaghan et al., 2012). Anti-VLA-4 antibody natalizumab has been evaluated as an alternative stromal adhesion-disruptive drug (Mraz et al., 2011). Finally lenalidomide, an immunomodulatory drug clinically active in several mature $B$ cell malignancies and under evaluation in FL, could disrupt B cell-stroma interaction through a decrease in both CXCL12 production by stromal cells (Wobus et al., 2012) and RhoH expression in malignant B cells (Troeger et al., 2012). Interestingly, the Btk inhibitor PCI-32765 has been initially developed to target BCR signaling but it also impairs the chemokine-induced adhesion and migration of primary chronic lymphocytic leukemia B cells (de Rooij et al., 2012). Similar results have been obtained with Syk and PI3K inhibitors and a recent study suggests that the Syk-mTOR pathway is involved in FL cell invasion, through the regulation of

\section{REFERENCES}

Amé-Thomas, P., Le Priol, J., Yssel, H., Caron, G., Pangault, C., Jean, R., Martin, N., Marafioti, T., Gaulard, P., Lamy, T., Fest, T., Semana, G., and Tarte, K. (2012). Characterization of intratumoral follicular helper $\mathrm{T}$ cells in follicular lymphoma: role in the survival of malignant B cells. Leukemia 26, 1053-1063.

Amé-Thomas, P., Maby-El Hajjami, H., Monvoisin, C., Jean, R., Monnier, D., Caulet-Maugendre, S., Guillaudeux, T., Lamy, T., Fest, T., and Tarte, K. (2007). Human mesenchymal stem cells isolated from bone marrow and lymphoid organs support tumor Bcell growth: role of stromal cells in follicular lymphoma pathogenesis. Blood 109, 693-702.

Bende, R. J., Smit, L. A., and Van Noesel, C. J. (2007). Molecular pathways in follicular lymphoma. Leukemia 21, 18-29.

Bognar, A., Csernus, B., Bodor, C., Reiniger, L., Szepesi, A., Toth, E., Kopper, L., and Matolcsy, A. (2005). Clonal selection in the bone marrow involvement of follicular lymphoma. Leukemia 19, 1656-1662.

Burger, J. A., Ghia, P., Rosenwald, A., and Caligaris-Cappio, F. (2009). The microenvironment in mature B-cell malignancies: a target for new treatment strategies. Blood 114, 3367-3375.

metalloproteinase-9 (MMP-9) and angiogenesis, as an upstream regulator of vascular endothelial growth factor (VEGF; Fruchon et al., 2012). Collectively, these results demonstrate that these antagonists of BCR-related kinases could also affect lymphoma cell homing and retention within specific niches. Surface molecules, growth factors, or signaling pathways involved in the bidirectional crosstalk between malignant B cells and stromal cells also represent individual attractive therapeutic targets even if the causative lymphoma-driven signals remain to be precisely defined.

\section{CONCLUDING REMARKS}

In vitro and in vivo studies corroborate the hypothesis that lymphoid BM and LN stromal cells play a central role in the development, growth, progression, and drug resistance in FL. The mechanisms of the crosstalk between malignant B cells and stromal cells are currently the subject of intensive research and several major questions remain unsolved. Whether or not the concept of cancer stem cells applies to this disease and, if true, what are their specific cell niches remains to be explored and could have major therapeutic consequences. Another important issue is the specificity of FL cell niches. Are they shared with premalignant follicular-lymphoma like cells or are they progressively induced by the contact with malignant cells? A detailed comparison of stromal cell niches in BM versus LN and their longitudinal study at diagnosis in the context of minimal residual disease and in relapse would be helpful to define the minimal but essential cell components that support FL cells and rescue them from drug cytotoxicity. It has also to be understood how such a supportive stromal microenvironment is assembled, in particular outside LN. The exact origin of ectopic FRC and FDC, and their relationships with local MSC should be further analyzed. Finally, developing new tools to better understand the functional heterogeneity of FL stroma may provide innovative strategies to disarm the vicious circle where stromal cells support malignant B cells that in turn convert their niche into a fully supportive microenvironment.

\section{ACKNOWLEDGMENTS}

This work was supported by research grants from the Institut National du cancer (INCa), the Ligue Régionale contre le Cancer, and the Fondation ARC pour la Recherche sur le Cancer.

Canioni, D., Brice, P., Lepage, E., Chababi, M., Meignin, V., Salles, B., Xerri, L., Peaud, P. Y., Rousselot, P., Peuchmaur, M., Solal-Celigny, P., and Brousse, N. (2004). Bone marrow histological patterns can predict survival of patients with grade 1 or 2 follicular lymphoma: a study from the Groupe d'Etude des Lymphomes Folliculaires. Br. J. Haematol. 126, 364-371.

Cattoretti, G., Mandelbaum, J., Lee, N., Chaves, A. H., Mahler, A. M., Chadburn, A., Dalla-Favera, R., Pasqualucci, L., and MacLennan, A. J. (2009). Targeted disruption of the S1P2 sphingosine 1-phosphate receptor gene leads to diffuse large
B-cell lymphoma formation. Cancer Res. 69, 8686-8692.

Chang, K. C., Huang, X., Medeiros, L. J., and Jones, D. (2003). Germinal centre-like versus undifferentiated stromal immunophenotypes in follicular lymphoma. J. Pathol. 201, 404-412.

Coelho, V., Krysov, S., Ghaemmaghami, A. M., Emara, M., Potter, K. N., Johnson, P., Packham, G., MartinezPomares, L., and Stevenson, F. K. (2010). Glycosylation of surface Ig creates a functional bridge between human follicular lymphoma and microenvironmental lectins. Proc. Natl. Acad. Sci. U.S.A. 107, 18587-18592. 
Crotty, S. (2011). Follicular helper CD4 T cells (TFH). Annu. Rev. Immunol. 29, 621-663.

Dave, S. S., Wright, G., Tan, B., Rosenwald, A., Gascoyne, R. D., Chan, W. C., Fisher, R. I., Braziel, R. M., Rimsza, L. M., Grogan, T. M., Miller, T. P., Leblanc, M., Greiner, T. C., Weisenburger, D. D., Lynch, J. C., Vose, J., Armitage, J. O., Smeland, E. B., Kvaloy, S., Holte, H., Delabie, J., Connors, J. M., Lansdorp, P. M., Ouyang, Q., Lister, T. A., Davies, A. J., Norton, A. J., Muller-Hermelink, H. K., Ott, G., Campo, E., Montserrat, E., Wilson, W. H., Jaffe, E. S., Simon, R., Yang, L., Powell, J., Zhao, H., Goldschmidt, N., Chiorazzi, M., and Staudt, L. M. (2004). Prediction of survival in follicular lymphoma based on molecular features of tumor-infiltrating immune cells. N. Engl. J. Med. 351, 2159-2169.

de Rooij, M. F., Kuil, A., Geest, C. R., Eldering, E., Chang, B. Y., Buggy, J. J., Pals, S. T., and Spaargaren, M. (2012). The clinically active BTK inhibitor PCI-32765 targets B-cell receptor- and chemokine-controlled adhesion and migration in chronic lymphocytic leukemia. Blood 119, 2590-2594.

Dierks, C., Grbic, J., Zirlik, K., Beigi, R., Englund, N. P., Guo, G. R., Veelken, H., Engelhardt, M., Mertelsmann, R., Kelleher, J. F., Schultz, P., and Warmuth, M. (2007). Essential role of stromally induced hedgehog signaling in B-cell malignancies. Nat. Med. 13, 944-951.

Epron, G., Ame-Thomas, P., Le Priol, J., Pangault, C., Dulong, J., Lamy, T., Fest, T., and Tarte, K. (2012). Monocytes and $\mathrm{T}$ cells cooperate to favor normal and follicular lymphoma Bcell growth: role of IL-15 and CD40L signaling. Leukemia 26, 139-148.

Fruchon, S., Kheirallah, S., Al Saati, T., Ysebaert, L., Laurent, C., Leseux, L., Fournie, J. J., Laurent, G., and Bezombes, C. (2012). Involvement of the Syk-mTOR pathway in follicular lymphoma cell invasion and angiogenesis. Leukemia 26, 795-805.

Green, J. A., and Cyster, J. G. (2012). S1PR2 links germinal center confinement and growth regulation. Immunol. Rev. 247, 36-51.

Guilloton, F., Caron, G., Ménard, C., Pangault, C., Amé-Thomas, P., Dulong, J., De Vos, J., Rossille, D., Henry, C., Lamy, T., Fouquet, O., Fest, T., and Tarte, K. (2012). Mesenchymal stromal cells orchestrate follicular lymphoma cell niche through the CCL2-dependent recruitment and polarization of monocytes. Blood 119, 2556-2567.
Hu, Y., Gale, M., Shields, J., Garron, C., Swistak, M., Nguyen, T. H., Jacques, G., Fogle, R., Siders, W., and Kaplan, J. (2012). Enhancement of the anti-tumor activity of therapeutic monoclonal antibodies by CXCR4 antagonists. Leuk. Lymphoma 53, 130-138.

Husson, H., Freedman, A. S., Cardoso, A. A., Schultze, J., Munoz, O., Strola, G., Kutok, J., Carideo, E. G., De Beaumont, R., Caligaris-Cappio, F., and Ghia, P. (2002). CXCL13 (BCA-1) is produced by follicular lymphoma cells: role in the accumulation of malignant B cells. Br. J. Haematol. 119, 492-495.

Jin, M. K., Hoster, E., Dreyling, M., Unterhalt, M., Hiddemann, W., and Klapper, W. (2011). Follicular dendritic cells in follicular lymphoma and types of non-Hodgkin lymphoma show reduced expression of CD23, CD35 and CD54 but no association with clinical outcome. Histopathology 58, 586-592.

Kim, J., Kim, D. W., Chang, W., Choe, J., Kim, J., Park, C. S., Song, K., and Lee, I. (2012). Wnt5a is secreted by follicular dendritic cells to protect germinal center B cells via Wnt/Ca2+/NFAT/NF-kappaB-B cell lymphoma 6 signaling. J. Immunol. 188, 182-189.

Kim, J. E., Singh, R. R., Cho-Vega, J. H., Drakos, E., Davuluri, Y., Khokhar, F. A., Fayad, L., Medeiros, L. J., and Vega, F. (2009). Sonic hedgehog signaling proteins and ATP-binding cassette G2 are aberrantly expressed in diffuse large B-cell lymphoma. Mod. Pathol. 22, 1312-1320.

Launay, E., Pangault, C., Bertrand, P., Jardin, F., Lamy, T., Tilly, H., Tarte, K., Bastard, C., and Fest, T. (2012). High rate of TNFRSF14 gene alterations related to 1 p36 region in de novo follicular lymphoma and impact on prognosis. Leukemia 26, 559-562.

Lin, J., Lwin, T., Zhao, J. J., Tam, W., Choi, Y. S., Moscinski, L. C., Dalton, W. S., Sotomayor, E. M., Wright, K. L., and Tao, J. (2011). Follicular dendritic cell-induced microRNAmediated upregulation of PRDM1 and downregulation of BCL-6 in non-Hodgkin's B-cell lymphomas. Leukemia 25, 145-152.

Lopez-Giral, S., Quintana, N. E., Cabrerizo, M., Alfonso-Perez, M., Sala-Valdes, M., De Soria, V. G., Fernandez-Ranada, J. M., Fernandez-Ruiz, E., and Munoz, C. (2004). Chemokine receptors that mediate B cell homing to secondary lymphoid tissues are highly expressed in B cell chronic lymphocytic leukemia and non-Hodgkin lymphomas with widespread nodular dissemination. J. Leukoc. Biol. 76 , 462-471.

Lukacs-Kornek, V., Malhotra, D., Fletcher, A. L., Acton, S. E., Elpek, K. G., Tayalia, P., Collier, A. R., and Turley, S. J. (2011). Regulated release of nitric oxide by nonhematopoietic stroma controls expansion of the activated $\mathrm{T}$ cell pool in lymph nodes. Nat. Immunol. 12, 1096-1104.

Lwin, T., Crespo, L. A., Wu, A. Dessureault, S., Shu, H. B., Moscinski, L. C., Sotomayor, E., Dalton, W. S., and Tao, J. (2009). Lymphoma cell adhesion-induced expression of B cell-activating factor of the TNF family in bone marrow stromal cells protects nonHodgkin's B lymphoma cells from apoptosis. Leukemia 23, 170-177.

Lwin, T., Hazlehurst, L. A., Dessureault, S., Lai, R., Bai, W., Sotomayor, E. Moscinski, L. C., Dalton, W. S., and Tao, J. (2007). Cell adhesion induces p27Kip1-associated cell-cycle arrest through down-regulation of the SCFSkp2 ubiquitin ligase pathway in mantle cell and other nonHodgkin's B-cell lymphomas. Blood 110, 1631-1638.

Lwin, T., Lin, J., Choi, Y. S., Zhang, X., Moscinski, L. C., Wright, K. L., Sotomayor, E. M., Dalton, W. S., and Tao, J. (2010). Follicular dendritic cell-dependent drug resistance of non-Hodgkin lymphoma involves cell adhesion-mediated Bim down-regulation through induction of microRNA-181a. Blood 116, 5228-5236.

Maby-El Hajjami, H., Ame-Thomas, P., Pangault, C., Tribut, O., Devos, J., Jean, R., Bescher, N., Monvoisin, C., Dulong, J., Lamy, T., Fest, T., and Tarte, K. (2009). Functional alteration of the lymphoma stromal cell niche by the cytokine context: role of indoleamine-2,3 dioxygenase. Cancer Res. 69, 3228-3237.

Mraz, M., Zent, C. S., Church, A. K., Jelinek, D. F., Wu, X., Pospisilova, S. Ansell, S. M., Novak, A. J., Kay, N. E., Witzig, T. E., and Nowakowski, G. S. (2011). Bone marrow stromal cells protect lymphoma Bcells from rituximab-induced apoptosis and targeting integrin alpha4-beta-1 (VLA-4) with natalizumab can overcome this resistance. $B r$. $J$. Haematol. 155, 53-64.

Mueller, C. G., Boix, C., Kwan, W. H., Daussy, C., Fournier, E., Fridman, W. H., and Molina, T. J. (2007). Critical role of monocytes to support normal $B$ cell and diffuse large B cell lymphoma survival and proliferation. $J$. Leukoc. Biol. 82, 567-575.
Mueller, S. N., and Germain, R. N. (2009). Stromal cell contributions to the homeostasis and functionality of the immune system. Nat. Rev. Immunol. 9, 618-629.

Munoz, O., Fend, F., De Beaumont, R., Husson, H., Astier, A., and Freedman, A. S. (2004). TGFbetamediated activation of Smad1 in Bcell non-Hodgkin's lymphoma and effect on cell proliferation. Leukemia 18, 2015-2025.

O'Callaghan, K., Lee, L., Nguyen, N., Hsieh, M. Y., Kaneider, N. C., Klein, A. K., Sprague, K., Van Etten, R. A., Kuliopulos, A., and Covic, L. (2012). Targeting CXCR4 with cellpenetrating pepducins in lymphoma and lymphocytic leukemia. Blood 119, 1717-1725.

Oricchio, E., Nanjangud, G., Wolfe, A. L., Schatz, J. H., Mavrakis, K. J., Jiang, M., Liu, X., Bruno, J., Heguy, A., Olshen, A. B., Socci, N. D., Teruya-Feldstein, J., Weis-Garcia, F., Tam, W., Shaknovich, R., Melnick, A., Himanen, J. P., Chaganti, R. S., and Wendel, H. G. (2011). The Ephreceptor A7 is a soluble tumor suppressor for follicular lymphoma. Cell $147,554-564$

Pangault, C., Ame-Thomas, P., Ruminy, P., Rossille, D., Caron, G., Baia, M., De Vos, J., Roussel, M., Monvoisin, C., Lamy, T., Tilly, H., Gaulard, P., Tarte, K., and Fest, T. (2010). Follicular lymphoma cell niche: identification of a preeminent IL-4-dependent TFH-B cell axis. Leukemia 24, 2080-2089.

Park, C. S., Yoon, S. O., Armitage, R. J., and Choi, Y. S. (2004). Follicular dendritic cells produce IL15 that enhances germinal center B cell proliferation in membranebound form. J. Immunol. 173, 6676-6683.

Pasero, C., Speiser, D. E., Derre, L., and Olive, D. (2012). The HVEM network: new directions in targeting novel costimulatory/coinhibitory molecules for cancer therapy. Curr. Opin. Pharmacol. 12, 478485.

Pereira, J. P., Kelly, L. M., and Cyster, J. G. (2010). Finding the right niche: B-cell migration in the early phases of T-dependent antibody responses. Int. Immunol. 22, 413-419.

Qian, B. Z., Li, J., Zhang, H., Kitamura, T., Zhang, J., Campion, L. R., Kaiser, E. A., Snyder, L. A., and Pollard, J. W. (2011). CCL2 recruits inflammatory monocytes to facilitate breast-tumour metastasis. Nature 475, 222-225.

Rajnai, H., Bodor, C., Balogh, Z., Gagyi, E., Csomor, J., Krenacs, T., Toth, E., 
and Matolcsy, A. (2012). Impact of the reactive microenvironment on the bone marrow involvement of follicular lymphoma. Histopathology 60, E66-E75.

Rehm, A., Mensen, A., Schradi, K., Gerlach, K., Wittstock, S., Winter, S., Buchner, G., Dorken, B., Lipp, M., and Hopken, U. E. (2011). Cooperative function of CCR7 and lymphotoxin in the formation of a lymphoma-permissive niche within murine secondary lymphoid organs. Blood 118, 1020-1033.

Relander, T., Johnson, N. A., Farinha, P., Connors, J. M., Sehn, L. H., and Gascoyne, R. D. (2010). Prognostic factors in follicular lymphoma. J. Clin. Oncol. 28, 2902-2913.

Roca, H., Varsos, Z. S., Sud, S., Craig, M. J., Ying, C., and Pienta, K. J. (2009). CCL2 and interleukin-6 promote survival of human CD11b+ peripheral blood mononuclear cells and induce M2-type macrophage polarization. J. Biol. Chem. 284, 34342-34354

Roozendaal, R., and Mebius, R. E. (2011). Stromal cell-immune cell interactions. Annu. Rev. Immunol. 29, 23-43.

Roulland, S., Faroudi, M., Mamessier, E., Sungalee, S., Salles, G., and Nadel, B. (2011). Early steps of follicular lymphoma pathogenesis. Adv. Immunol. $111,1-46$.

Ruminy, P., Jardin, F., Picquenot, J. M., Parmentier, F., Contentin, N., Buchonnet, G., Tison, S., Rainville, V., Tilly, H., and Bastard, C. (2008). $\mathrm{S}(\mathrm{mu})$ mutation patterns suggest different progression pathways in follicular lymphoma: early direct or late from FL progenitor cells. Blood 112, 1951-1959.

Sacedon, R., Diez, B., Nunez, V., Hernandez-Lopez, C., GutierrezFrias, C., Cejalvo, T., Outram, S. V., Crompton, T., Zapata, A. G., Vicente, A., and Varas, A. (2005). Sonic hedgehog is produced by follicular dendritic cells and protects germinal center B cells from apoptosis. J. Immunol. 174, 1456-1461.

Shaffer, A. L. III, Young, R. M., and Staudt, L. M. (2012). Pathogenesis of human B cell lymphomas. Annu. Rev. Immunol. 30, 565-610.

Siegert, S., Huang, H. Y., Yang, C. Y., Scarpellino, L., Carrie, L., Essex, S., Nelson, P. J., Heikenwalder, M., Acha-Orbea, H., Buckley, C. D., Marsland, B. J., Zehn, D., and Luther, S. A. (2011). Fibroblastic reticular cells from lymph nodes attenuate $\mathrm{T}$ cell expansion by producing nitric oxide. PLOS ONE 6, e27618. doi:10.1371/journal.pone. 0027618

Singh, R. R., Kim, J. E., Davuluri, Y., Drakos, E., Cho-Vega, J. H., Amin, H. M., and Vega, F. (2010). Hedgehog signaling pathway is activated in diffuse large B-cell lymphoma and contributes to tumor cell survival and proliferation. Leukemia 24 , 1025-1036.

Stevenson, F. K., and Stevenson, G. T. (2012). Follicular lymphoma and the immune system: from pathogenesis to antibody therapy. Blood 119 , 3659-3667.

Thomazy, V. A., Vega, F., Medeiros, L. J., Davies, P. J., and Jones, D. (2003). Phenotypic modulation of the stromal reticular network in normal and neoplastic lymph nodes: tissue transglutaminase reveals coordinate regulation of multiple cell types. Am J. Pathol. 163, 165-174.

Tjin, E. P., Bende, R. J., Derksen, P. W., Van Huijstee, A. P. Kataoka, H., Spaargaren, M., and Pals, S. T. (2005). Follicular dendritic cells catalyze hepatocyte growth factor (HGF) activation in the germinal center microenvironment by secreting the serine protease HGF activator. J. Immunol. 175 , 2807-2813.

Tjin, E. P., Groen, R. W., Vogelzang, I. Derksen, P. W., Klok, M. D., Meijer, H. P., Van Eeden, S., Pals, S. T., and Spaargaren, M. (2006). Functional analysis of HGF/MET signaling and aberrant HGF-activator expression in diffuse large B-cell lymphoma. Blood 107, 760-768.

Troeger, A., Johnson, A. J., Wood, J., Blum, W. G., Andritsos, L. A., Byrd, J. C., and Williams, D. A. (2012). RhoH is critical for cell-microenvironment interactions in chronic lymphocytic leukemia in mice and humans. Blood 119, 4708-4718.

Vega, F., Medeiros, L. J., Lang, W. H., Mansoor, A., Bueso-Ramos, C. and Jones, D. (2002). The stromal composition of malignant lymphoid aggregates in bone marrow: variations in architecture and phenotype in different B-cell tumours. Br. J. Haematol. 117, 569-576.

Wahlin, B. E., Sander, B., Christensson, B., Ostenstad, B., Holte, H., Brown, P. D., Sundstrom, C., and Kimby, E. (2012). Entourage: the immune microenvironment following follicular lymphoma. Blood Cancer J. 2 , e52.
Wobus, M., Benath, G., Ferrer, R. A., Wehner, R., Schmitz, M., Hofbauer, L. C., Rauner, M., Ehninger, G., Bornhauser, M., and Platzbecker, U. (2012). Impact of lenalidomide on the functional properties of human mesenchymal stromal cells. Exp. Hematol. (in press).

Yoon, S. O., Zhang, X., Berner, P., Blom, B., and Choi, Y. S. (2009). Notch ligands expressed by follicular dendritic cells protect germinal center B cells from apoptosis. J. Immunol. 183, 352-358.

Conflict of Interest Statement: The authors declare that the research was conducted in the absence of any commercial or financial relationships that could be construed as a potential conflict of interest.

Received: 29 June 2012; accepted: 16 August 2012; published online: 05 September 2012.

Citation: Mourcin F, Pangault C, AminAli $R$, Amé-Thomas $P$ and Tarte $K$ (2012) Stromal cell contribution to human follicular lymphoma pathogenesis. Front. Immun. 3:280. doi: 10.3389/fimmu.2012.00280

This article was submitted to Frontiers in Antigen Presenting Cell Biology, a specialty of Frontiers in Immunology. Copyright (C) 2012 Mourcin, Pangault, Amin-Ali, Amé-Thomas and Tarte. This is an open-access article distributed under the terms of the Creative Commons Attribution License, which permits use, distribution and reproduction in other forums, provided the original authors and source are credited and subject to any copyright notices concerning any third-party graphics etc. 